\title{
Supervision of Post-graduate Students: A Faculty Case Study of Co-supervision at a University of Technology in South Africa
}

\author{
Letlhoyo Segalo \\ Department of Educational and Professional Studies, Central University of Technology, Free State, P.O. Box 1881 Mothusi Road \\ Thabong 9460, South Africa
}

Received January 17, 2021; Revised February 7, 2021; Accepted March 22, 2021

\section{Cite This Paper in the following Citation Styles}

(a): [1] Letlhoyo Segalo, "Supervision of Post-graduate Students: A Faculty Case Study of Co-supervision at a University of Technology in South Africa," Universal Journal of Educational Research, Vol. 9, No. 3, pp. 660 - 664, 2021. DOI: 10.13189/ujer.2021.090325.

(b): Letlhoyo Segalo (2021). Supervision of Post-graduate Students: A Faculty Case Study of Co-supervision at a University of Technology in South Africa. Universal Journal of Educational Research, 9(3), 660 - 664. DOI: 10.13189/ujer.2021.090325.

Copyright $\bigcirc 2021$ by authors, all rights reserved. Authors agree that this article remains permanently open access under the terms of the Creative Commons Attribution License 4.0 International License

\begin{abstract}
This paper recollects the experiences of co-supervision of 8 Masters (M.), 3 Doctoral students and 4 promoters and supervisors at the Faculty of Humanities. The aim of the study was to establish a sound understanding of co-postgraduate promotion and supervision at one Faculty at the University of Technology in South Africa. Co-postgraduate student supervision implies more than one supervisor, at times two and in rare cases three. This multifaceted supervision approach is referred to as a safety net. On the one hand, co-postgraduate students' supervision could be framed as multi-voiced dialogue process with the aim to enhance the quality of research done by the postgraduate student. At times, this approach is said to bring along a negative dimension for the student and supervisors. A qualitative research case study using an interpretivist approach was used. For both the promoters/supervisors and postgraduate students, an open-ended questionnaire was used. A thematic data analysis was used. The findings of this study both from the students and supervisors' experiences unearthed an understanding that underpins past and present practices of co-post-graduate supervision for future practices.
\end{abstract}

Keywords Co-supervision, Post-graduate Student, Disciplines, University of Technology, Interpretivist

\section{Introduction}

In this study, a framework of co-post-graduate supervision of Master and Doctoral students is explored. The process of post-graduate student supervision is tedious and a lengthy one involving the aspiration and expectation of the student, the research study and supervisors respectively. As such, a post-graduate supervision of post-graduate students at university is one of the most salient tasks of the study leaders. Its purpose is either to prepare the student for Doctoral studies in Masters and a licentia in Doctoral studies. Another task of student postgraduate supervision is to enable an environment of independence for the student to become a professional researcher and a scholar in the domain or field of his /her research focus [1]. The process of student supervision involves interaction of the study supervisor with the student which at time could be emotive if the roles and responsibilities of all the stakeholders are not transparently addressed [1] [2]. [3] Support this statement by stating that communication between the supervisor/s and the student is a key which identifies important issues that should be addressed before the study could commence.

In view of the foregoing argument, [4] augment that the supervisor/s plays a critical role in the socialization (academic culture) of the student. This academic acculturation might involve one supervisor model or dual 
model supervision. Dual student supervision model in the context of this study refers to a situation where the research study of the student is supervised by more than one supervisor/s. These secondary supervisors are referred to as co-supervisors or co-promoters of the student. [5] Further offers a managerial model of post-graduate student supervision which encompasses the supervisor as a knowledge expert and as the manager of the student research process. This postulation of [5] assumes that both the lead student supervisor and the co-supervisor must be equally knowledgeable and have the managerial acumen to lead the research process.

\section{Co-supervision of Postgraduate Students}

Co-supervision of post-graduate students is referred to synonymously as joint-supervision or team supervision [6]. Co-postgraduate student supervision presupposes that in the context of post-graduate supervision there will be the main or lead supervisor and other supporting supervisors selected on their fields of specialty and technical skills [6]. Co-post-graduate supervision departs from one traditional model where there is only one supervisor where it is the sole responsibility of the research leader to induct, guide and socialize the post-graduate in the scholarly community [17][8]. [9] have conceptualized post-graduate supervision as a professional work which cut across different disciplines and comprises five facets which are the learning alliance, habits of the mind, scholarly expertise, techne and contextual expertise. These are five facets of student post-graduate supervision which assumes what a supervisor should have. It will thus seem daunting to assume that one supervisor will exhibit all the five competencies, henceforth the conceptualization of a co-post-graduate supervision.

The composition of the research team might follow an experienced supervisor with a novice supervisor model [10]. Based on this model, it could be implied that the bulk of the supervisory work will be done by the experienced supervisor. On the other hand, the role of the novice researcher will be that of learning. It is the assumption of this research that this model might be risky especially if the novice researcher is co-supervising at a doctoral level.

Studies conducted in co-post-graduate indicate the discrepancies in social sciences in relation to other disciplines such as natural sciences and engineering [8]. Irrespective of the discipline, [11] indicate that there are vast advantages of co- supervision for both the lead supervisor and the post-graduate student. For; example, in a co-post-graduate supervision milieu the student is exposed to a variety of intellectual perspectives and expertise across a variety of professional discipline [12][13]. Likewise, co-post-graduate supervision could expose the student to tension and confusion when roles and responsibilities of all the stakeholders are not clearly communicated [14]. It is therefore important for the lead supervisor; the co-supervisor and the student understand what roles would be played by each other in the research process [15][16].

In a South African context co-supervision in postgraduate programmes could be justified as the aim of the Department of Higher Education is to increase throughputs rate [17][18][19]. Therefore, the importance of redressing and creating a just society based on democratic values such as equality, non-racialism, and improvement of the quality of life cannot be overemphasized. The advent of historical mergers of universities in South Africa adds to a skewed research output. Studies show that former White universities continue to lead in research as compared to the historically Black universities. As such, the transformation of higher education landscape as pronounced in the White Paper 3 on higher education in South Africa might remain a mirage [20].

\section{Materials and Methods}

The aim of this study was to comprehend the institutional practices of co-supervision of post-graduate student at the Faculty of Humanities at a University of Technology (UoT) in a South African context. Therefore, the objective of the research study was to explore the current institutional practices of post-graduate supervision across faculties,

The research question that underpinned this research was whether there was a need to have a common approach to co-supervision of post-graduate students at a university of technology in South Africa or not.

An interpretative, qualitative research design was selected in this study as it was fit for the purpose of embracing the subjective perspectives views held by participants and their conscious thoughts [21][22][23]. As the study investigated the ontological reality of co-postgraduate supervision at one university of technology in South Africa, the intention was not to generalize but to understand what co-postgraduate supervision practices existed at the faculty of Humanities at one UoT in South Africa [24][25]. The interpretivist approach employed in this research study embraces the epistemic notions which allows co-postgraduate student' supervisors to converse naturally and subjectively, without prejudice [26].

A purposive sample of 4 post-graduate supervisors with varying supervision experience was conducted in one faculty of the Humanities. A further purposive sample of 8 graduated Masters and 3 doctoral students was followed. In both cases an open-ended questionnaire was employed to illicit institutional and personal experiences of co-supervisory models that are used across different faculties and postgraduate experiences of co-supervisory 
teams [27].

The ethical stance in the context of this research study was informed by [22] when referring to qualitative data gathering as a construction site for knowledge which should be viewed as a moral inquiry. Furthermore, [23] further stress ethics as the ability of the researcher to predict the consequences of actions, with rightness or wrongness being dependent on the consequences of the act. As a result of these notions, ethical clearance was requested and granted by the University Ethical Committee; henceforth, participation in this research was voluntary and the participants were anonymous.

[27] posits that the focal point of qualitative research data analysis is to describe what is happening, and that the description should be detailed and should contribute to an understanding of the setting being studied. This guidance of [28] was used to provide a thorough description of what postgraduate supervisors and postgraduate students relate to, in the case of co-student postgraduate supervision as a pedagogical practice. A thematic data analysis was used to identify patterns and categorize the main themes emerging from both supervisors and students [29]. The use of a thematic data analysis was used to bring forth a narrative reporting on the expressions of the participants and was triangulated through the literature review.

\section{Results and Discussion}

The findings discussed in this paper are centred on the experiences of co-post-graduate supervision of supervisors and graduated master and doctoral students at one university of technology in South Africa. Post-graduate supervisors responded to the institutional culture and practice on co-post-graduate supervision. On the other hand, the master and doctoral students responded to the question on how they perceived and experienced co-supervision.

Themes that emerged from the open-ended questionnaire with the supervisors were analysed as follows:

\section{Theme1: Institutional policy on co-supervision}

The response below belongs to a supervisor from the faculty of Humanities. His response affirms that there was no institutional policy in place to regulate post-graduate co-research supervision.

"There is no policy. It could be used to indicate procedure that should be followed in co-supervisor. It would indicate it the following:

- The roles of the co-supervisors

- Communication channels between the supervisors and the student

- All research protocols that should be followed during co-supervision"
This response of the supervisor resonated with the responses of other supervisors that there was no institutional policy on co-supervision. This evidence suggests that research supervisors in their own faculties assume what the roles and responsibilities could be. Evidence further suggests that there are no common institutional practices of co-supervision in place.

\section{Theme2: Choice of a co-supervisory team}

The choice of co-supervisor is supposedly informed by the five facets model as conceptualized by [4][12]. Contrarily, there are many factors that contribute to the choice of a co-supervisor. Lead supervisors seem not to have a choice in deciding that a co-supervisor could be as the staff capacity in each faculty could determine who a co-supervisor could be. This is captured in the reflection of the female supervisor in the faculty of Health and Environmental Sciences

"We have a small capacity for supervision in the department. We decide at programme meetings who supervisor and co-supervisors will be based on workload ad supervision capacity"

This view was different from the view of the supervisor in Humanities who contrasted:

"Yes, I have a role. For an internal co-supervisor, I complete the necessary form and indicate the name of the preferred co-supervisor. I give reasons why I propose the person to co-supervise. For an external co-supervisor, I also complete the corresponding form and indicate the name of the preferred co-supervisor. I give reasons why I propose the person to co-supervise. I also attached a $\mathrm{cv}$ of the proposed co-supervisor for final decision by the HOD”

It would seem justifiable for the lead supervisor to have a choice in choosing a co-supervisor in the study of the student in order to avoid misunderstandings and impositions that could be detrimental to the supervisory milieu for the student.

\section{Theme3: Communication model with the student}

Communication model where the lead supervisor co-supervisor and the student decode at the onset of the research study plays an important role in establishing a conducive environment to initiate the research process. Evidence emanating from the open-ended questionnaire suggests that a lead supervisor will initiate the process until such time the proposal has been completed that the cosupervisor is involved in the study.

"No. I do not. I usually complete the research proposal with the students. Thereafter, the student submits the research proposal to the co-supervisor who works with the student to finalize it" 
It will seem appropriate to have the lead supervisor and the co-supervisor working together from the onset. [32] attest that a sound communication model can address issues of power and authority between the lead supervisor and the co-supervisor. This process will assist in drawing the parameters and roles, responsibilities, and expectations of al the stakeholders involved. [33] state that common understanding is important in co-supervision as it delineates responsibilities among decision makers, that is the lead supervisor and the co-supervisor.

\section{Theme4: Reporting back strategies to the student}

Studies on postgraduate supervision in South Africa show that there is no uniform practice when supervisor and co-supervisor must report to the student [20] [9]. Each supervisor and co- supervisor device their own way of handling the report processes as indicated by one lead supervisor by stating the following:

"There is no strategy, this process is done separately. The co-supervisor and I usually do not meet in order to minimize academic conflicts. "I involve the co-supervisor when I am satisfied that the research proposal makes sense. Thereafter, the student submits chapters to the co-supervisor and me. The students will receive inputs from the co-supervisor and me. The student will integrate the inputs and resubmit the chapter to each one of us. Where there are different opinions, the student selects what is best for his/her study"

The above-mentioned statement could have negative implications for the post-graduate student as the student might not know whose comments should be accepted.[33] say that misunderstanding and conflicts among supervisor and the co-supervisor are unavoidable due to different personalities, cultures as well as different levels of experiences.

\section{Theme5: Post-graduate students' experiences on co-supervision}

The following findings of the research study are that of the experiences of the Master and Doctoral students who have since graduated in the last three years from the faculty. Their insight and experiences were assumed to be critical to the study. From a client's perspective, it would suggest that the participation of the student in deciding who the supervisor or co-supervisor of the study is crucial. Evidence suggests that students are not made aware of their rights to choose who their study leaders would be. At times the students surrender their right to participate in bona fide hoping that it is the right thing. On the one hand, students, out of ignorance or lack of knowledge, do not do their background research on the expertise and technical skills of their study leaders [30]. Most of the advice given on the research project was done by the main supervisor. The co-supervisor mainly focused on administrative issues that leads to the completion of the study. A Master of Education student mentioned the following when asked about the efficacy of feedback from the co-supervisor:

"The feedback received from the supervisor was effective, constructive and helpful. My supervisor also arranged one-on-one meetings which took place after each chapter was submitted. The supervisor always recommended changes to the submitted work"

The excerpt in the above lines suggests that postgraduate students felt comfortable with the main supervisor. When asked which mode of supervision a Doctoral student is likely to prefer, one person or two promoting or supervising his studies, the student elaborated:

"Based on my experience, I would prefer only the main supervisor. The views from the supervisor are very important, because they improve the quality of the research being done. He/she can identify mistakes that one should take note of and improve on"

The findings from the postgraduate students imply that they prefer a one-supervisor model of student supervision. Again, [32] agree that co-supervision can be time-consuming as it seems to delay the progress of the student. Again, postgraduate students seem to be not aware of their choices when deciding on the supervision of their studies.

\section{Conclusions}

It is safe to suggest that based on the evidence arising from the open-ended questionnaire with both the supervisors and the post-graduate students it seems that there is no common ground regarding the decisions on co-supervision. As indicated earlier in the findings, lack of institutional policy on co-supervision might lead to a point where disjuncture between the student and the research environment is created. It would seem proper to suggest that the research student is properly oriented about how the scholarly community functions to enable him to fully participate in the different roles that he/she is supposed to play. Reporting guidelines between the lead supervisor and the co-supervisor to the student should be outlined in order to minimize misunderstandings for the student.

\section{REFERENCES}

[1] H. Friedrich, -Nel, J.L. Mackinnon. Expectations in postgraduate supervision: perspectives from supervisors and doctoral students. INTERIM, 12(1), 1-14. 2013.

[2] L. Le Grange, R. Newmark. Postgraduate research supervision in a socially distributed knowledge system: some thoughts, 16(3), 50-57. 2002. 
[3] A. Lee. How are doctoral students supervised? Concepts of doctoral research supervision. Studies in Higher Education, 267-281. 2008.

[4] O. Dysthe. Professors as mediators of academic text cultures: an interview with advisors and master's degree students in three disciplines in a Norwegian university. [5 Written Communication, 19(4), 485. 2002.

[5] T. Vilkinas, T. (2002). The PhD process: the supervisor as manager. Education \& Training, 44(3), 129-137. 2002.

[6] C. Pole. Joint supervision and the $\mathrm{PhD}$ : safety net or panacea? Assessment \& Evaluation in Higher Education 23(3), 259-271. 1998.

[7] C. Pole. Joint supervision and the PhD: safety net or panacea? Assessment. 2002.

[8] G. Pillay, R.J. Balfour. Postgraduate supervision practices in South African universities in the era of democracy and educational change 1994-2004. South African Journal of Higher Education, 25(2), 358-371. 2011.

[9] K. Lahenius, H, Ikavalko. Joint supervision practices in doctoral education- A student experience. Journal of Further and Higher Education, 1, 1-20. 2012.

[10] C. OHalse, J. Malfroy. Retheorising doctoral supervision as professional work. Studies in Higher Education, 35(1), 79-92. 2010.

[11] J.H. Watts. Team supervision of the doctorate: managing roles, relationships and contradictions. Teaching in Higher Education, 15(3), 335-339. 2010.

[12] S. Kobayashi, B. Grout, C. Rump. Interaction and learning in $\mathrm{PhD}$ supervision with multiple supervisors. Temaartikel, Argang, 8(14), 13-25. 2013.

[13] O. Dysthe, A. Samara, K, Westrheim. Multivoiced supervision of master's students: a case study of alternative supervision practices in higher education. Studies in Higher Education, 31(3), 299-318. 2006.

[14] N.Z. Abiddin, A. Ismael, A. Ismael. Effective supervisory approach in enhancing postgraduate research studies. International Journal of Humanities and Social Science, 1(2), 206-217. 2011.

[15] A.Ismael, N.Z, Abiddin, A. Hassan. Improving the development of postgraduates' research and supervision. International Education Studies, 4(1), 78-89. 2011.

[16] N. Lessing, A.C. Lessing. The supervision of research for dissertations and theses. Acta Commerccili, 4, 73-87. 2004.

[17] M.M. Nkoane, D. Francis, S.M.G. Mahlomaholo. Exploration of the critical relationship between higher education and the development of democracy in South
Africa. South Africa Journal of Higher Education, 28(3), 673-677. 2014.

[18] J.A. van Biljon, M.R. de Villiers. Multiplicity in supervision models: The supervisor's perspective. South African Journal of Higher Education, 27(6), 1443-1463. 2013.

[19] P. Ngulube. Improving the quality of research outputs in higher education through knowledge sharing and collaboration: a case study. Mousaion, 23(1), 39-61. 2005.

[20] J.L. Le Grange, K.J. Walters. The lived experience of Online Educators: Hermeneutic phenomenology. Journal of Online Learning and Teaching, 6(2), 357-366. 2010.

[21] E. R. Babbie, J. Mouton. The practice of social research. New York: Oxford University Press. 2001.

[22] J.A. Smith, M. Osborn. Interpretive Phenomenological Analysis. In: Smith, J.A. (ed.) Qualitative Psychology: A practical guide to research methods. 2nd ed.Los Angeles California: Sage. 2009.

[23] H. Strydom, C.S.L. Delport. Sampling and pilot study in qualitative research. In: De Vos, A.S., Strydom, H., Fouché, C.B. \& Delport, C.S.L. (eds.) Research at grass roots, for the social science and human service professions. 4th ed. Pretoria: Van Schaik. 2011.

[24] J. Creswell. Qualitative inquiry \& research design: choosing among fiveapproaches. 3rd ed. Thousand Oaks, CA: Sage Publications. 2013

[25] G. Payne, J. Payne. Key concepts in social research. Sage Publications: London. 2004.

[26] S, Kvale. Doing interviews. Los Angeles: Sage Publications. 2010.

[27] N. King, C. Horrocks. Interviews in qualitative research. New York: Sage Publications. 2010.

[28] U. Flick. Designing qualitative research. Los Angeles: Sage Publications. 2010.

[29] V. Braun, V. Clarke. Using thematic analysis in psychology. Qualitative research in psychology, 3(2), 77-101. 2006.

[30] S, Schulze. Students' reflections on postgraduate research. Progressio, 34(1), 41-55. 2012.

[31] P. Olmos-López, J. Sunderland. Doctoral supervisors' and supervisees' responses to co-supervision, Journal of Further and Higher Education, 41:6, 727-740, 2017. DOI: 10.1080/0309877X.2016.1177166.

[32] B.T. Johansen, R..M Olsen, N.C. Øverby, R. Garred, E. Enoksen. Team supervision of doctoral students: A qualitative inquiry. International Journal of Doctoral Studies, 14, 69-84. 2019. https://doi.org/10.28945/4177. 